\title{
Laguncularia racemosa (Combretaceae) y bacterias terrestres asociadas medio siglo después de la contaminación crónica por hidrocarburos
}

\author{
José Guadalupe López-Jiménez¹, María del Carmen Rivera-Cruz ${ }^{1 *}$, Antonio Trujillo-Narcía², \\ Lorenzo Armando Aceves-Navarro ${ }^{1}$, Ángel Sol-Sánchez ${ }^{1} \&$ Omar Sarracino-Martínez ${ }^{2}$ \\ 1. Colegio de Postgraduados Campus Tabasco. Laboratorio de Microbiología Agrícola y Ambiental. Periférico Carlos A. \\ Molina s/n km 3.5, H. Cárdenas, Tabasco, México. CP 86570; mariari@colpos.mx \\ 2. Cuerpo Académico Energía y Medioambiente. Universidad Popular de la Chontalpa. Carretera Cárdenas - \\ Huimanguillo km 2, H. Cárdenas, Tabasco, México. CP 86500. \\ * Correspondencia
}

Recibido 08-I-2019. Corregido 04-VI-2019. Aceptado 16-IX-2019.

\begin{abstract}
Laguncularia racemosa (Combretaceae) and associated ground bacteria half a century after chronic oil pollution. The evaluation of the impact of oil on the soil-root interaction of the white mangrove plant, Laguncularia racemosa is essential to identify changes in microbial activity and biotechnological potential for remediation contaminated Histosols. The objective was to evaluate the spatial distribution of total petroleum hydrocarbons (THP) in organic soil, the population density of plant growth promoting bacteria, also in microbial respiration in the rhizoplane (RI), rhizosphere (RZ) and in non-rhizospheric soil (NRS) of $L$. racemosa. An area of $8000 \mathrm{~m}^{2}$ of an affected Histosol was evaluated, during 1967 and 1968, by chronic oil spill and drilling mud from the La Venta 248 oil well. Fifteen trees of this species were selected to obtain samples of the RI, RZ and NRS. The TPH were extracted in soxhlet with dichloromethane for eight hours and quantified by gravimetry. The average amount extracted from TPH allowed the differentiation of four soils (S) from the evaluated area, the average values were for S1: $1797 \mathrm{mg} \mathrm{kg}^{-1}$ (not contaminated for Mexican regulations) and three contaminated soils, the values are S2: 3 294, S3: 5 249, and S4: $10389 \mathrm{mg} \mathrm{kg}^{-1}$. The results show statistical differences (Duncan, $\mathrm{p} \leq 0.05$ ) between means of the evaluated variables. The greatest accumulation of TPH was $22962 \mathrm{mg} \mathrm{kg}^{-1}$, it was extracted from the NRS in S4. The highest densities of N-fixing bacteria (NFB), P solubilizers, Azospirillum and Azotobacter were biostimulated by the presence of high levels of THP in the soil, however microbial respiration was inhibited. The results suggest that L. racemosa is sustainable in soils with weathering oil, and is a biostimulator of microbial activity for natural attenuation.
\end{abstract}

Key words: Azospirillum, Azotobacter, N-fixing bacteria, P solubilizers, white mangrove, respiration.

López-Jiménez, J. G., Rivera-Cruz, M. C., Trujillo-Narcía, A., Aceves-Navarro, L. A., SolSánchez, A. \& Sarracino-Martínez, O. (2019). Laguncularia racemosa (Combretaceae) y bacterias terrestres asociadas medio siglo después de la contaminación crónica por hidrocarburos. Revista de Biología Tropical, 67(6), 1194-1209.

Los manglares son bosques tropicales localizados en la transición entre la plataforma continental y el mar, representan ecosistemas productivos (Kathiresan \& Qasim, 2005; Quirós-Rodríguez, Medrano-Mangones, \& Santafé-Patiño, 2017) que aportan abundante materia orgánica en el suelo y en zona rizoférica. Este ecosistema natural es sensible a los cambios de la calidad del agua en regiones costeras, así se ha demostrado por los efectos de derrames de petróleo (Duke \& Watkinson, 2002; Zhang, Cai, Yuan, \& Chen, 2004). Al respecto, reportes científicos encontraron acumulación de hidrocarburos del petróleo en suelos con bosques 
de mangle en China, Australia, Japón, Kenia, Nigeria, Estados Unidos, región del Mar Caribe, Brasil, Colombia y México (Burns \& Codi, 1998; Proffitt \& Devlin, 1998; Duke \& Watkinson, 2002; Zhang et al., 2004; Ke, Yu, Wong, \& Tam, 2005; Tam, Wong, \& Wong, 2005; Gundlach, 2018).

El contacto de la planta de mangle con la película o sobrenadante del petróleo dispersada por el agua, impregna la raíz, el tallo, ramas y las hojas. El efecto del petróleo es variado en la planta. En el caso de la raíz diferentes estudios explican que exuda moléculas de bajo peso molecular fácilmente disponibles para la nutrición de los microorganismos del suelo (Demoling, Figueroa, \& Baath, 2007; Marschner, 2012). El RI es la zona inmediata exterior a la epidermis radical en la región de la corteza, es colonizado por bacterias diazotróficas (Marschner, 2012; Neumann \& Römheld; 2012), la RZ es el suelo adherido a la raíz, su extensión varía de un $\mu \mathrm{m}$ a varios centímetros (Hinsinger, Gobran, Gregory, \& Wenzel, 2009).

En el RI y en la RZ ocurre la interacción entre la planta y los microorganismos fundamentales en el proceso de la nutrición, en la salud de la planta y en la estructura de las comunidades microbianas (Berg \& Smalla, 2009). Las extensiones del RI y de la RZ varían según los tipos de planta y del suelo. El mangle blanco se caracteriza porque posee sistema radical fúlcreo en forma de zanca o clavija arriba y debajo de la superficie, de la base del fuste se originan raíces primarias con crecimiento horizontal y lateral, de ellas se forman raíces verticales enterradas en el suelo. La raíz tiene estructura intrincada, posee tejidos de ventilación (lenticelas), crece en suelos orgánicos y anegados con altos contenidos de materia orgánica (Purnobasuky \& Suzuki, 2005; Dueñas \& Nieto, 2010). Estas características forman un microbioma con intensa actividad microbiana que es importante en la transformación de la materia orgánica, también contribuye en el suministro de nutrimentos a los organismos asociados con el ecosistema del manglar (Kathiresan, 2011; Saravanakumar, Anburaj, Gomathi, \& Kathiseran, 2016).

El RI y la RZ del mangle hospedan bacterias promotoras de crecimiento vegetal $\mathrm{BPCV}$ que intervienen en los ciclos del carbono, azufre, nitrógeno y del fósforo (Rojas, Holguin, Glick, \& Bashan, 2001). Los grupos y géneros incluyen bacterias diazotróficas fijadoras de $\mathrm{N}$ de vida libre (Azotobacter spp y Azospirillum spp) y bacterias solubilizadoras de fosfato BSP involucradas en el reciclado de carbono bajo condiciones óxicas y anóxicas del manglar (Das et al., 2012; García, 2015). La respiración microbiana, evaluada a través del $\mathrm{CO}_{2}$ liberado a la atmosfera, ha sido estudiada como indicador del metabolismo de las poblaciones microbianas en el suelo (Pepper \& Gerba, 2015). Resultados de investigaciones indican que la actividad microbiana y las densidades poblacionales de BFN de vida libre y BSP en el RI y en la RZ, sostienen el equilibrio del ecosistema de pantano, a través de la disponibilidad de nutrimentos para los organismos vivos y la degradación de los hidrocarburos del petróleo (Rivera-Cruz, Trujillo-Narcía, Trujillo-Rivera, Arias-Trinidad, \& Mendoza-López, 2016; Rodríguez-Rodríguez, Rivera-Cruz, TrujilloNarcía, Almaraz-Suárez, \& Salgado-García, 2016; Morales-Guzmán et al., 2017). Considerando que existe mayor actividad microbiana en el RI y en la RZ por la presencia de exudados radicales, esta investigación busca responder si en el RI y en la RZ de la planta de mangle blanco se acumula el petróleo, si ahí ocurre intensa respiración microbiana, y si existen BPCV en presencia de niveles que rebasen los $3000 \mathrm{mg}$ de HTP.

Los objetivos fueron, primero, evaluar la distribución espacial de los hidrocarburos totales del petróleo (HTP) en el RI y en la RZ de la planta de mangle blanco y en el SNR; segundo, estudiar la capacidad de L. racemosa para el alojamiento de rizobacterias y bioestimulación de la respiración microbiana en diferentes espacios de la interacción suelo-raíz de un Histosol contaminado con petróleo intemperizado desde 1967. Se proponen dos hipótesis, primero, la concentración de HTP es mayor en RI y en la RZ que en el SNR; segundo, sólo las concentraciones de $10389 \mathrm{mg} \mathrm{kg}^{-1}$ HTP intemperizado inducen diferencias en las densidades poblacionales de BFN de vida libre, BSP, Azospirillum y Azotobacter; y en la respiración microbiana. 


\section{MATERIALES Y MÉTODOS}

Área de estudio y condiciones ambientales: El área de estudio está ubicada en la cuenca baja del Río Tonalá en el sureste de México (Fig. 1), a $1.2 \mathrm{~km}$ al oeste del Complejo Procesador de Gas La Venta. Las coordenadas UTM del polígono son 388170 a 388300 y 2000320 a 2000380 en Zona 15. El área evaluada abarca $8000 \mathrm{~m}^{2}$ de un Histosol impactado desde 1967 por derrames crónicos de petróleo y de lodos de perforación del pozo petrolero La Venta 248 (Orocio, 2014). En términos taxonómicos el suelo es un Histosol con horizonte superficial fíbrico (10-0 $\mathrm{cm}$ de profundidad), otro hémico $(0-32 \mathrm{~cm})$, uno sáprico $(32-45 \mathrm{~cm})$ y a mayor profundidad $(>45 \mathrm{~cm})$ existe suelo mineral, aparentemente relacionado con el relleno de la construcción del terraplén del pozo petrolero. El Histosol permanece inundado la mayor parte del año, recibe la influencia diaria de la marea desde el Golfo de México, a través del Río Tonalá (Fig. 1). El bosque de mangle es de origen natural, tiene $15 \pm 5.8 \mathrm{~m}$ de altura, el diámetro del tallo a $1.5 \mathrm{~m}$ de altura es $44.6 \pm$ $19.75 \mathrm{~cm}$. El clima es tropical húmedo con lluvias en verano, la precipitación anual acumulada es $2024.1 \mathrm{~mm}, 1169.1 \mathrm{~mm}$ de evaporación y la temperatura alcanza un promedio anual de
$26.4{ }^{\circ} \mathrm{C}$ (Díaz, Ruiz, Medina, Cano, \& Serrano, 2006).

Muestreos de rizósfera, rizoplano y suelo no rizosférico: El muestreo fue dirigido y estratificado en función de la cantidad visible de petróleo acumulado en el suelo y de la ubicación de la raíz de la planta de mangle. $\mathrm{La}$ cantidad visible de petróleo en el suelo se complementó con la intensidad de la iridiscencia observable sobre la superficie de la columna del agua, ambos criterios se conjuntaron para la clasificación de tres zonas de interés del área estudiada: baja, media y alta cantidad de petróleo en el suelo orgánico. Se seleccionaron 15 árboles distribuidos en $8000 \mathrm{~m}^{2}$ del Histosol (Fig. 1), en seguida se ubicaron dos puntos de muestreo a $50 \mathrm{~cm}$ de distancia al norte y al sur del tallo de cada árbol, después se definieron tres zonas de muestreo en la profundidad 0-30 $\mathrm{cm}$ : RZ, constituida por el suelo adherido a la raíz a una distancia máxima de cinco $\mathrm{mm}$ de la misma; RI, es la raíz pero sin suelo, separado en forma manual; por último, el SNR, correspondió al suelo sin raíz. Se colectaron, por separado, muestras compuestas a partir de tres submuestras, de la RI y del RZ, el suelo orgánico se extrajo con pala recta y la raíz se cortó con cuchillo esterilizado. Las muestras
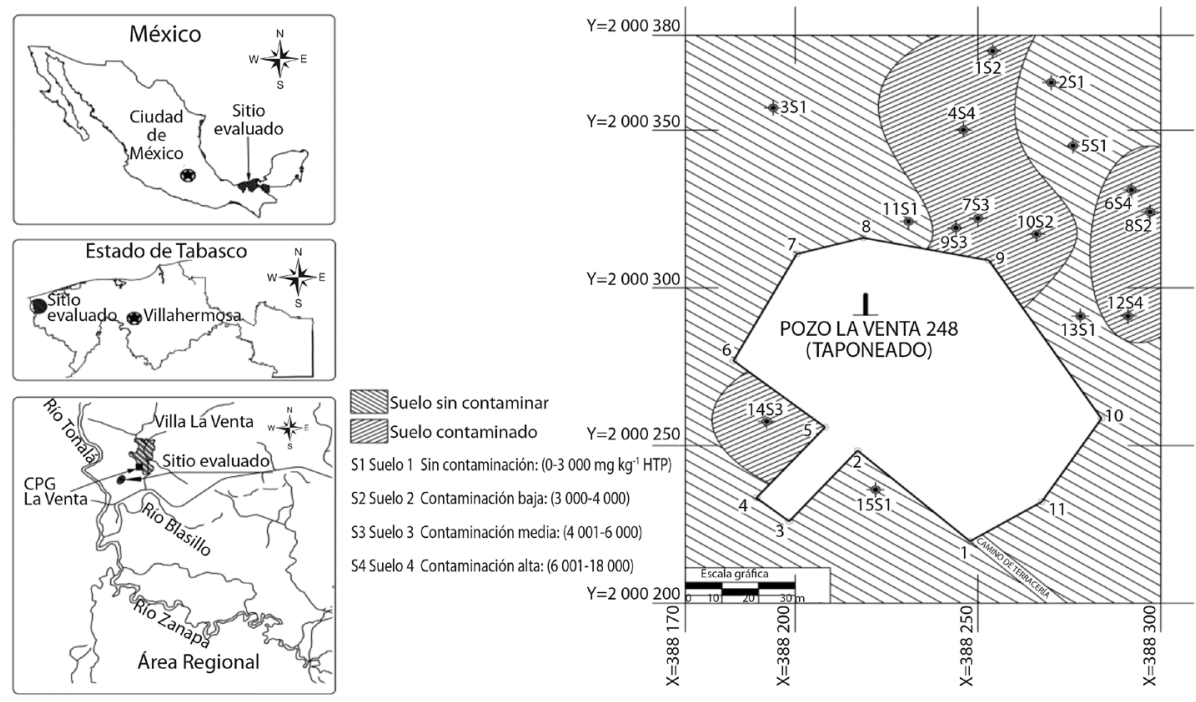

Fig. 1. Bosque de mangle blanco (Laguncularia racemosa) en el ejido José Narciso Rovirosa, Huimanguillo, Tabasco, México. 
del SNR se extrajeron con nucleador cerrado de acero inoxidable, también se conformaron con tres repeticiones. El total de muestras fueron 90: 30 de RI, 30 de RZ y 30 de SNR, cada muestra se introdujo en un frasco de vidrio esterilizado, de $0.25 \mathrm{~kg}$ de capacidad, con tapa de teflón, se etiquetó y se preservó en campo dentro de hielera con hielo. El mismo día de la colecta se transportaron al laboratorio y se preservó a $4{ }^{\circ} \mathrm{C}$. Las variables evaluadas fueron HTP, densidad de BPCV, respiración microbiana y variables físicas y químicas del suelo. Las características físicas clase textural, humedad del suelo, y las químicas $\mathrm{pH}$, conductividad eléctrica, materia orgánica, nitrógeno total y fósforo disponible fueron determinadas según las rutinas analíticas especificadas en la NOM-021-RECNAT-2000 (SEMARNAT, 2002). Los resultados analíticos de los cuatro suelos (Fig. 1) tienen las siguientes características: textura franco-arcillosa (hidrometría), humedad 59 a $65 \%$ (gravimetría), 4.5 a 5 de $\mathrm{pH}$ (potenciometría), conductividad eléctrica varió de 4625 a $5373 \mu \mathrm{s} / \mathrm{cm}$ (extracto de saturación), 9.31 a $18.6 \%$ de materia orgánica (combustión seca), 0.29 a $0.38 \%$ nitrógeno total (micro-Kjeldhal) y 387 a $526 \mathrm{mg} \mathrm{kg}^{-1}$ de fósforo disponible.

Hidrocarburos totales del petróleo: Se utilizó $10 \mathrm{~g}$ de suelo para la extracción del petróleo intemperizado en equipo soxhlet mediante el método 3540B (USEPA, 1996). La muestra compuesta contiene una mezcla desconocida de tipo de petróleo derramado en el suelo desde el inicio de operación del pozo petrolero La Venta 248 a partir de 1967 (Orocio, 2014). La muestra se acidificó con $\mathrm{HCl}$, después se secó con $\mathrm{MgSO}_{4}$. El solvente diclorometano grado analítico se evaporó durante ocho horas y el peso seco del extracto se cuantificó por gravimetría.

Clasificación y delimitación del suelo según hidrocarburos totales del petróleo: $\mathrm{Se}$ realizó el mapeo de los $8000 \mathrm{~m}^{2}$ en función de la cantidad de HTP extraído del suelo. El criterio básico fue el límite máximo permisible establecido en la normativa mexicana para suelo con uso forestal (SEMARNAT, 2013), el valor máximo permitido es $3000 \mathrm{mg} \mathrm{kg}^{-1}$. Las áreas definidas fueron el suelo 1 (S1) con 0 a $3000 \mathrm{mg} \mathrm{kg}^{-1}$ de HTP, este es el suelo clasificado como no contaminado. Los contaminados son el S2 con 3001 a $4000 \mathrm{mg}$, el S3 con 4001 a $6000 \mathrm{mg}$ y, por último, el S4 varió de 6001 a 18000 mg (Fig. 1). La delimitación de las cuatro áreas se definió con el valor promedio de las muestras analizadas. Los valores fueron 1797 $\pm 103 \mathrm{mg}$ HTP para S1, el S2 fue $3294 \pm 271$ $\mathrm{mg}$, el valor del S3 fue $5249 \pm 432 \mathrm{mg}$, y para el S4 aumentó a $10389 \pm 1019$ mg de HTP.

Densidades poblaciones y aislados de bacterias: Las densidades poblacionales de las BPCV se contaron de las muestras de RI, RZ y SNR de los cuatro suelos ya especificados. Este estudio se realizó con el método de dilución seriada y determinación de cuenta viable en cajas Petri (Madigan, Martinko, Dunlap, \& Clark, 2015). Se utilizó el medio de cultivo carbón combinado para BFN de vida libre (Rennie, 1981), rojo congo para el grupo Azospirillum (Reinhold et al., 1987), el medio Ashby para el grupo Azotobacter (Döbereiner, Marriel, \& Nery, 1976) y el denominado Pikovskaya para BSP (Pikovskaya, 1948). Los efectos RI y RZ se determinaron dividiendo las densidades bacterianas del RI y de RZ entre la densidad del SNR de cada suelo (Atlas \& Bartha, 2002).

Actividad microbiana: La actividad microbiana se evaluó durante 63 d para la cuantificación de la respiración microbiana ( $\mathrm{mg} \mathrm{CO}_{2} \mathrm{~g}^{-1} \mathrm{~d}^{-1}$ ) liberada de L. racemosa, de la RZ y del SNR. El experimento fue un factorial $3 \times 4 \times 5$, el factor 1 fue el tipo de suelo (RI, RZ y SNR), el factor 2 fue la cantidad promedio de HTP en cuatro suelos $(1797,3294,5249$ y $10389 \mathrm{mg} \mathrm{kg}^{-1}$ ) y el factor 3 el tiempo de incubación $(7,14,21,42$ y 63 d). Cada tratamiento se evaluó con seis repeticiones. La unidad experimental fue un frasco estéril de vidrio, con tapa, de $1.0 \mathrm{~kg}$ de capacidad, se introdujo $100 \mathrm{~g}$ de muestra fresca y se evaluó con el método de incubación por fumigación (Jenkinson, 1976), la incubación fue a $28^{\circ} \mathrm{C}$. La humedad se mantuvo a $60 \%$ para simular las condiciones in situ del Histosol. Se introdujo en el frasco un vial 
con $15 \mathrm{~mL}$ de $\mathrm{NaOH} 1 \mathrm{M}$, el $\mathrm{CO}_{2}$ liberado de la muestra quedó atrapado en el $\mathrm{NaOH}$, el vial se extrajo el día 7, el $\mathrm{NaOH}$ se tituló con $\mathrm{HCl}$ $1 \mathrm{M}$ en presencia de $\mathrm{BaCl}_{2}$ y fenolftaleína. Este procedimiento se repitió, con nuevos viales, los días 14, 21, 42 y 63. Se cuantificó el $\mathrm{CO}_{2}$ acumulado en cada tiempo de incubación.

Análisis estadístico: El análisis de varianza (ANOVA) de cada variable fue realizado con el programa Statistical Analysis System versión 8.01 (SAS, 2005). La determinación de diferencias de medias de HTP en muestras de RI, RZ y SNR en los cuatro tipos de suelo fue con la prueba de Duncan $(\mathrm{p} \leq 0.05)$. Se utilizó el mismo criterio para el cálculo de las medias de las poblaciones de BFN de vida libre, poblaciones de BSP, Azospirillum y Azotobacter, además para la respiración microbiana $\left(\mathrm{CO}_{2}\right.$ liberado).

\section{RESULTADOS}

Hidrocarburos totales del petróleo: Las medias de las cantidades de los HTP extraídos del suelo tienen diferencias estadísticas

Suelo 1
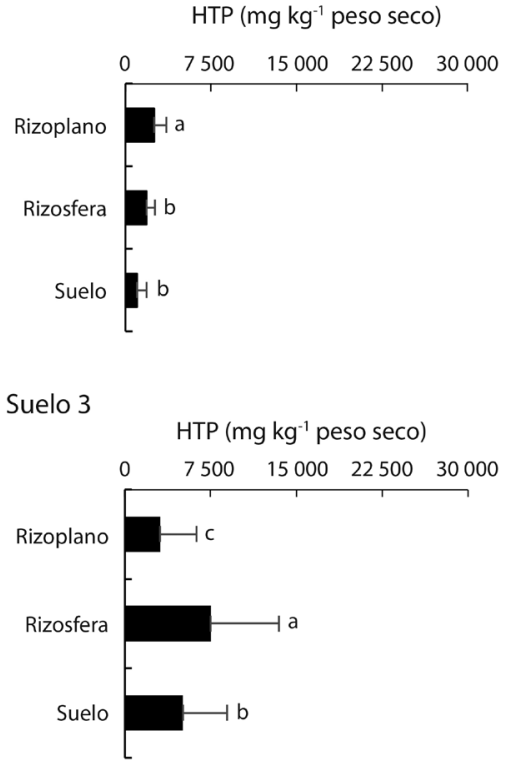

(Duncan, $\mathrm{p} \leq 0.05$ ), además la cantidad de petróleo excedió el límite máximo permisible de $3000 \mathrm{mg}$ en suelo con uso forestal (SEMARNAT, 2013). Por otro lado, las medias de las cantidades de HTP tienen diferencias estadísticas entre el RI, RZ y en el SNR (Fig. 2). Los mayores contenidos de petróleo en el RI se encontraron en S2 y S3, en la RZ se extrajo de los suelos S3 y S4, y en SNR se localizó en el suelo S4. El nivel de contaminación en el RI fue $2.5,1.5$ veces mayor y 0.6 y 0.1 veces menor que el SNR de los suelos S1, S2, S3 y $\mathrm{S} 4$, respectivamente. En RZ los contenidos de HTP fueron $1.8,1.0$ y 1.5 mayor $\mathrm{y}, 0.3$ veces menor que en el SNR de los suelos S1, S2, S3 y S4, respectivamente. Los índices de HTP entre RI y SNR fueron mayores en el S1; el índice fue 2.5, y en S2, disminuyó a 1.5. En el S2 el mayor contenido fue encontrado en el RI (4 $158 \mathrm{mg} \mathrm{kg}^{-1}$ ), en el S3 la mayor concentración se encontró en RZ con 7513 mg. Los resultados promedios correspondientes al RI, RZ y al SNR en el S4 fueron 2305, 5900 y $22962 \mathrm{mg} \mathrm{kg}^{-1}$, respectivamente. Estas concentraciones de petróleo están relacionadas con el derrame crónico proveniente de la perforación

Suelo 2

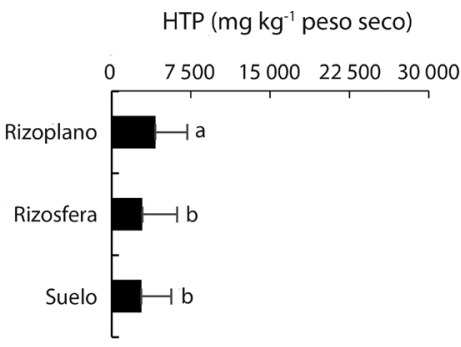

Suelo 4

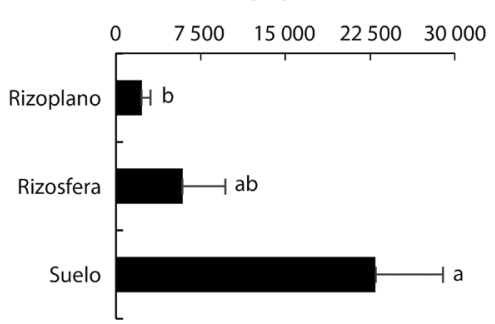

Fig. 2. Distribución espacial de hidrocarburos totales del petróleo, en la profundidad 0-30 cm, en cuatro suelos del bosque de mangle blanco (Laguncularia racemosa). Letras diferentes en cada suelo indican diferencias estadísticas (Duncan, $\mathrm{p} \leq$ $0.05, \mathrm{n}=12)$. 
y operación del pozo petrolero La Venta 248 (Fig. 1 y Fig. 2). Otra probable fuente es por el arrastre de petróleo derramado en sitios aledaños al Río Tonalá (Fig. 1), mismo que se comunica con una dársena, y que llega hasta el sitio evaluado por el efecto de la marea cada 12 h desde el Golfo de México.

Densidad poblacional y aislados de bacterias: Las poblaciones de BFN, BSP, Azotobacter spp y de Azospirillum spp mostraron diferencias estadísticas significativas en cada uno de los cuatro suelos. Las poblaciones de tres grupos de rizobacterias (BFN, BSP y $A z O-$ tobacter) fueron mayores en el RI respecto al RZ y SNR en dos suelos (S1 y S4) (Tabla 1). Las mayores densidades poblacionales de BFN $\left(84 \times 10^{3}\right.$ UFC) y de BSP $\left(105 \times 10^{3}\right.$ UFC) creció en el RI del suelo con mayor contaminación (S4), la del grupo Azotobacter (25 y $24 \times 10^{3}$ UFC) en el RI de los S1 y S2. La densidad de Azospirillum (71 y $67 \times 10^{3}$ UFC) fue mayor solo en la RZ de los suelos S2 y S3 (Tabla 1). Respecto al grupo de BFN en RI, RZ y
SNR (con valores promedios 55,50 y $23 \times 10^{3}$ UFC, respectivamente), $\operatorname{BSP}\left(65,58\right.$ y $\left.20 \times 10^{3}\right)$, Azospirillum (42, 57 y $27 \times 10^{3}$ ) fueron mayores en suelo contaminado con petróleo (Fig. 3B), pero Azotobacter con 25, 12 y $14 \times 10^{3}$ fueron mayores en suelo sin contaminación (Fig. 3A).

El incremento de la densidad poblacional en los cuatro suelos varió de 1.9 a 3.1 veces de BFN en RI y 1.3 a 2.6 en la RZ respecto al SNR (Tabla 1). Similares incrementos se constataron en las densidades de las BSP en RI y RZ, los valores fluctuaron de 1.8 a 8.1 y de 1.7 a 5.1 veces, respectivamente; de la misma manera la densidad de Azospirillum fue estimulada en el RI, los valores fluctuaron entre 1.4 a 1.5, en RZ fue de 1.2 a 3.2 veces (Tabla 2) mayor densidad poblacional respecto a los valores en el SNR. Sin embargo, la densidad poblacional de $\mathrm{AzO}$ tobacter aumentó de 1.3 a 2.4 veces en el RI. En el suelo sin contaminación los cuatro grupos de bacterias fueron mayores en el RI (Fig. 3).

El efecto del RI en la diversidad de aislados de Azospirillum y Azotobacter fue observado al incrementarse 1.1 y 1.2 veces (Tabla 2 )

TABLA 1

Densidades poblacionales de diferentes grupos de bacterias en rizoplano, rizósfera de Laguncularia racemosa y en suelo no rizosférico en área contaminada con petróleo intemperizado

\begin{tabular}{|c|c|c|c|}
\hline Suelo/HTP $\left(\mathrm{mg} \mathrm{kg}^{-1}\right)$ & Rizoplano & Rizósfera & Suelo no rizosférico \\
\hline \multicolumn{4}{|c|}{ Fijadoras de $\mathrm{N}$ de vida libre $\left(10^{3} \mathrm{UFC}^{-1}\right.$ s.s. $)$} \\
\hline S1: 1797 & $35 \mathrm{bc} c^{\S}$ & $22 \mathrm{c}$ & $17 \mathrm{c}$ \\
\hline S2: 3294 & $49 \mathrm{abc}$ & $49 \mathrm{abc}$ & $26 \mathrm{c}$ \\
\hline S3: 5249 & $34 \mathrm{bc}$ & $29 \mathrm{c}$ & $16 \mathrm{c}$ \\
\hline \multirow[t]{2}{*}{ S4: 10389} & $84 \mathrm{a}$ & $71 \mathrm{ab}$ & $27 \mathrm{c}$ \\
\hline & \multicolumn{3}{|c|}{ Solubilizadoras de fosfato $\left(10^{3} \mathrm{UFC}^{-1}\right.$ s.s. $)$} \\
\hline S1: 1797 & 40bcd & 44bcd & $23 \mathrm{~cd}$ \\
\hline S2: 3294 & $58 \mathrm{abcd}$ & $81 \mathrm{ab}$ & $34 \mathrm{bcd}$ \\
\hline S3: 5249 & $33 \mathrm{bcd}$ & $28 \mathrm{~cd}$ & $13 \mathrm{~d}$ \\
\hline \multirow{2}{*}{ S4: 10389} & $105 \mathrm{a}$ & $66 \mathrm{abc}$ & $13 \mathrm{~d}$ \\
\hline & \multicolumn{3}{|c|}{ Azotobacter $\left(10^{3} \mathrm{UFC}^{-1}\right.$ s.s. $)$} \\
\hline S1: 1797 & $25 \mathrm{a}$ & $12 \mathrm{ab}$ & $14 \mathrm{ab}$ \\
\hline S2: 3294 & $24 \mathrm{ab}$ & $15 \mathrm{ab}$ & $18 \mathrm{ab}$ \\
\hline S3: 5249 & $19 \mathrm{ab}$ & $8 \mathrm{~b}$ & $8 b$ \\
\hline \multirow[t]{2}{*}{ S4: 10389} & $3 b$ & $8 \mathrm{ab}$ & $13 \mathrm{ab}$ \\
\hline & \multicolumn{3}{|c|}{ Azospirillum (10 ${ }^{3} \mathrm{UFC}^{-1}$ s.s.) } \\
\hline S1: 1797 & $45 \mathrm{ab}$ & $40 \mathrm{ab}$ & $32 \mathrm{ab}$ \\
\hline S2: 3294 & $56 \mathrm{ab}$ & $68 \mathrm{a}$ & $26 a b$ \\
\hline S3: 5249 & $41 \mathrm{ab}$ & $33 \mathrm{ab}$ & $28 \mathrm{ab}$ \\
\hline S4: 10389 & $30 \mathrm{ab}$ & $67 \mathrm{a}$ & $21 \mathrm{~b}$ \\
\hline
\end{tabular}

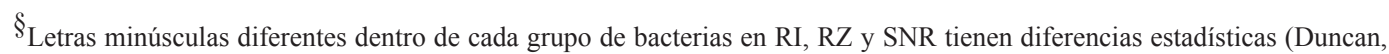
$\mathrm{P} \leq 0.05, \mathrm{~S} 1 \mathrm{n}=36, \mathrm{~S} 2 \mathrm{n}=18, \mathrm{~S} 3 \mathrm{n}=18, \mathrm{~S} 4 \mathrm{n}=18)$. Letras mayúsculas diferentes por suelo entre espacios son diferentes estadísticamente (Duncan $\mathrm{P} \leq 0.05$ ). 

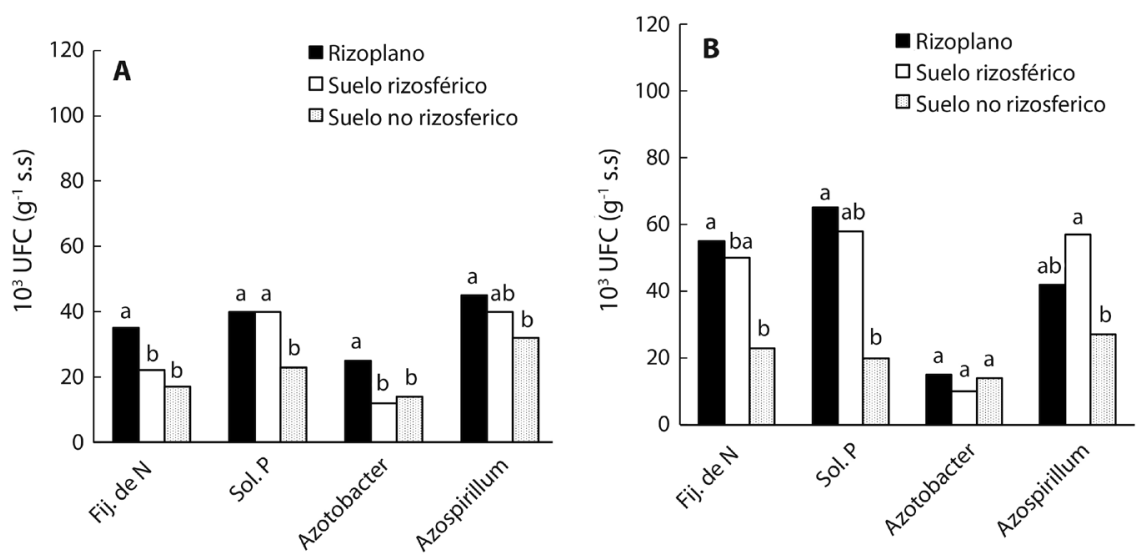

Fig. 3. Densidad poblacional de rizobacterias en rizosplano, rizósfera y en suelo no rizosférico en suelo sin petróleo (A) y con petróleo intemperizado (B), en el bosque de Laguncularia racemosa. Letras minúsculas diferentes dentro de cada grupo bacteriano indica diferencias estadísticas (Duncan, $\mathrm{P} \leq 0.05, \mathrm{n}=12$ ).

TABLA 2

Efectos en rizoplano y rizósfera de Laguncularia racemosa, en histosol con y sin petróleo, según densidad poblacional de bacterias promotoras del crecimiento vegetal y respiración basal

\begin{tabular}{|c|c|c|c|c|c|c|c|c|}
\hline \multirow{3}{*}{$\begin{array}{c}\text { Espacio/ } \\
\text { suelo/petróleo } \\
\left(\mathrm{mg} \mathrm{kg}^{-1}\right)\end{array}$} & \multicolumn{7}{|c|}{ Bacterias promotoras del crecimiento vegetal } & \multirow{3}{*}{ Respiración basal } \\
\hline & \multicolumn{4}{|c|}{ Densidad poblacional } & \multicolumn{3}{|c|}{ Diversidad } & \\
\hline & BFN & BSP & Azot & Azop & BSP & Azot & Azop & \\
\hline \multicolumn{9}{|l|}{ Rizoplano } \\
\hline S1: 1797 & 2.1 & 1.7 & 1.8 & 1.4 & 1 & 1 & 1 & 1.6 \\
\hline S2: 3294 & 1.9 & 1.7 & 1.3 & 1.8 & 1 & 1 & 1.2 & 2.1 \\
\hline S3: 5249 & 2.1 & 2.6 & 2.4 & 1.5 & 1 & 1.3 & 1 & 1.6 \\
\hline S4: 10389 & 3.1 & 8.1 & 1.5 & 1.4 & 1 & 1 & 1.5 & 1.6 \\
\hline \multicolumn{9}{|l|}{ Rizósfera } \\
\hline S1: 1797 & 1.3 & 1.7 & 0.9 & 1.3 & 1 & 1 & 1 & 1.4 \\
\hline S2: 3294 & 1.9 & 2.7 & 0.8 & 2.0 & 0.8 & 1.2 & 1.2 & 1.5 \\
\hline S3: 5249 & 1.8 & 2.2 & 1 & 1.2 & 1 & 1 & 1 & 1.3 \\
\hline S4: 10389 & 2.6 & 5.1 & 0.6 & 3.2 & 0.8 & 1.5 & 1 & 1.9 \\
\hline \multicolumn{9}{|l|}{ Sin petróleo } \\
\hline Rizoplano & 2.1 & 1.7 & 1.8 & 1.4 & 1 & 1 & 1 & 1.6 \\
\hline Rizósfera & 1.3 & 1.7 & 1.7 & 1.3 & 1 & 1 & 1 & 1.4 \\
\hline \multicolumn{9}{|l|}{ Con petróleo } \\
\hline Rizoplano & 2.4 & 4.1 & 0.9 & 1.2 & 1 & 1.1 & 1.2 & 1.8 \\
\hline$\underline{\text { Rizósfera }}$ & 2.1 & 3.3 & 0.8 & 2.2 & 0.9 & 1.2 & 1.1 & 1.6 \\
\hline
\end{tabular}

respecto al SNR en el S4. Se distingue el efecto RZ en suelo contaminado en la diversidad de Azotobacter con una relación de 1.2 veces mayor respecto al SNR (Tabla 2).

Actividad microbiana: La respiración microbiana fue mayor en el RI a los 7, 14, 21, 42 y 63 días después de la incubación. En los cinco tiempos la respiración basal microbiana fue menor en la RZ y fue mayor en el SNR. La respiración basal en $\mathrm{S} 1$ (sin petróleo), S2, S3 y S4 (con petróleo) en los tres espacios muestra una curva sigmoidea (Fig. 4). Al principio de la incubación (día 7) la respiración fue menor o igual a $17 \mathrm{mg}$ de $\mathrm{CO}_{2}$ g suelo $^{-1} \mathrm{~d}^{-1}$ en el RI, RZ y en el SNR para todos los suelos, aumentó en forma paulatina hasta alcanzar el valor máximo el día 21 entre 32 a $67 \mathrm{mg}$ de $\mathrm{CO}_{2}$, y disminuyó hasta 4-23 mg de $\mathrm{CO}_{2}$ en la cuantificación realizada el día 63 . 

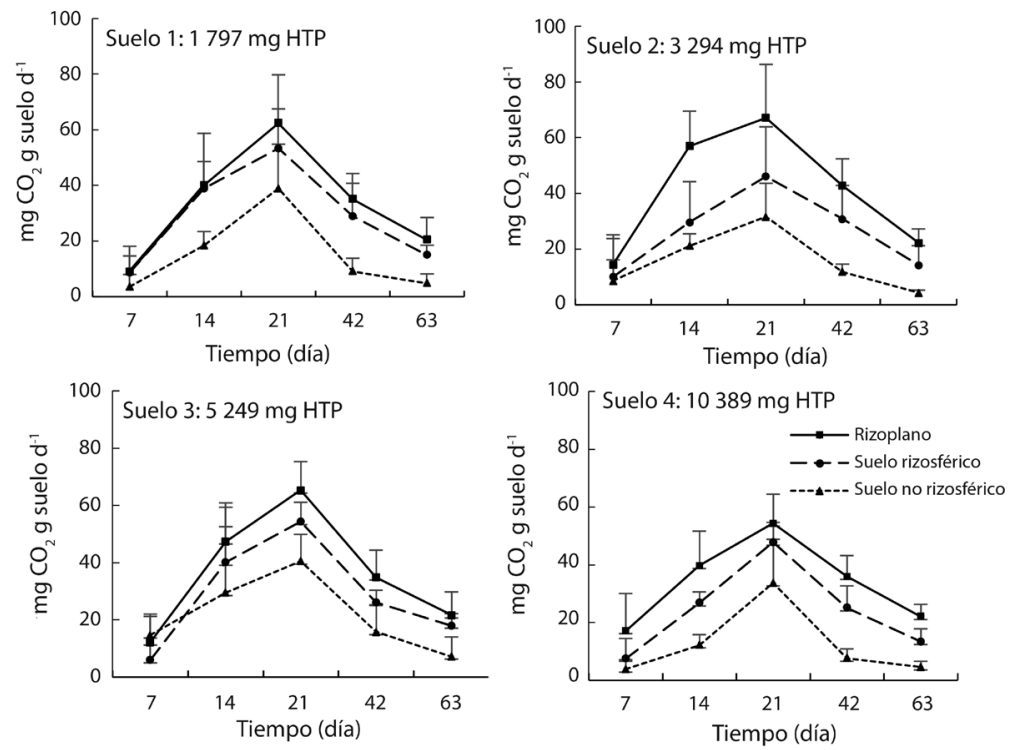

Fig. 4. Liberación de $\mathrm{CO}_{2}$ de la respiración microbiana en rizoplano, suelos rizosférico y no rizosférico de la planta de mangle blanco (Laguncularia racemosa) en cuatro suelos contaminados con petróleo intemperizado $(\mathrm{n}=12)$.

El RI, y menor grado la RZ, estimuló la respiración microbiana con respecto al SNR en los cuatro suelos. Los de la respiración en el RI registró valores máximos al día 21 con $62 \mathrm{mg} \mathrm{CO}$ fueron 62 en $\mathrm{S} 1$ sin contaminación, aumentó a 67,65 y 54 en los suelos S2, S3 y S4, respectivamente. La RI el día 21 alcanzó $53,47,54$ y $48 \mathrm{mg} \mathrm{CO}$ en los cuatro suelos evaluados con una relación entre el RI y la RZ de $1.2,1.4,1.2$ y 1.1. La menor respiración basal con 39, 32, 40 y $34 \mathrm{mg} \mathrm{CO}_{2}$ fue en el
SNR de los S1, S2, S3 y S4, respectivamente (Fig. 4).

La curva-respuesta de la emisión de $\mathrm{CO}_{2}$, en el RI, RZ y en el SNR, en suelo contaminado registró a través del tiempo una forma sigmoidea con valores máximos el día 21 de 60 , 49.6 y $32 \mathrm{mg} \mathrm{CO}$ (Fig. 5A), respectivamente. Esto es una disminución de 3.2, 6.4, $17.9 \%$ respecto a los espacios similares en suelo no contaminado (Fig. 5B).
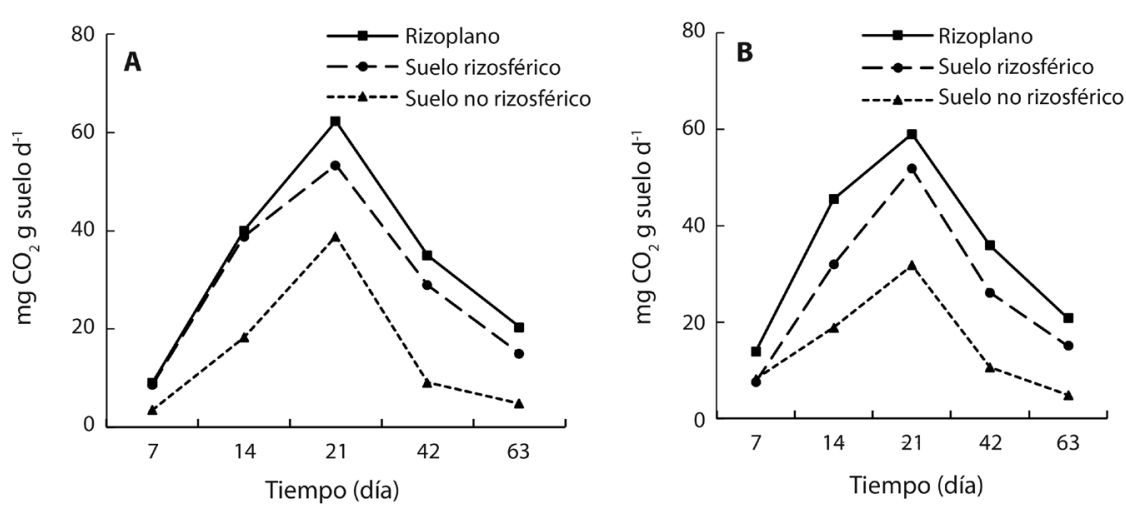

Fig. 5. Producción diaria de $\mathrm{CO}_{2}$ en muestras de rizoplano, rizósfera y suelo no rizosférico sin petróleo (A) y contaminado con petróleo intemperizado (B), durante cinco momentos (días). 


\section{DISCUSIÓN}

Efecto de la contaminación por petróleo crudo en el contenido de petróleo: Esta investigación es uno de los primeros estudios que muestra la importancia del bosque de mangle blanco (L. racemosa) para el establecimiento de rizobacterias y el metabolismo microbiano en el RI, RZ en suelos con petróleo intemperizado en una región tropical. Los HTP derivados del petróleo están presentes en el RI y en la RZ de $L$. racemosa y en SNR espesor de 0-30 cm en los cuatro suelos evaluados. Se han reportado resultados similares en tierras subyacentes a instalaciones petroleras: entre 4947 a 14250 y 65890 a $118789 \mathrm{mg} \mathrm{kg}^{-1}$ de HTP (Rivera-Cruz et al., 2016; Rodríguez-Rodríguez et al., 2016; Trujillo-Narcía, Rivera-Cruz, Trujillo-Rivera, \& Roldán-Garrigos, 2018). Little, Holtzmann, Gundlach y Galperin (2018) estudiaron un suelo de bosque de manglar contaminado con petróleo crudo crónico, encontraron que en el espesor de $0-15 \mathrm{~cm}$ fue mayor el contenido de hidrocarburos (43208 mg kg$~^{-1}$ ) y en la capa subyacente entre $15-30 \mathrm{~cm}$ disminuyó a 14601 mg kg-1 HTP. Similares resultados encontraron Rivera-Cruz, Ferrera-Cerrato, Volke, Rodríguez y Fernández (2002) en Gleysol histieutri-sódico con derrame crónico de petróleo con 9110 a $322841 \mathrm{mg} \mathrm{kg}^{-1}$ acumulados en el horizonte subsuperficial (profundidad, 17-25 y 25-34 cm). Estos autores mencionan que la retención de petróleo se debe al alto contenido de la materia orgánica, cantidad de raíces en Gleysol y los poros más pequeños en horizontes subyacentes, ya que el movimiento del petróleo depende de poros del suelo. La cantidad mayor de HTP en el RI y RZ en el S2, S3 y S4 sugiere que el RI y RZ de L. racemosa retiene petróleo que el agua mueve en el bosque de manglar. La fuente del petróleo suspendido en el agua puede proceder de capas subyacentes de S3 y S4 con 7 515, 5108, 5900 y $22962 \mathrm{mg}$ $\mathrm{kg}^{-1}$ HTP localizados en espesor entre 10 a 30 $\mathrm{cm}$. Los hidrocarburos se liberan por el flujo constante del agua y por densidades diferentes emerge en la superficie reteniéndose en el RI y en la RZ. El flujo del agua en el bosque del manglar, según Orihuela, Tovilla, Franciscus y Álvarez (2004), es derivado de la marea diaria, la cual arrastra materiales orgánicos de menor densidad que el agua.

La acumulación de petróleo en suelo del manglar ha sido reportado en diferentes profundidades (Burns \& Codi, 1998) a $40 \mathrm{~cm}$, también a $20 \mathrm{~cm}$ (Little et al., 2018). Estos autores explican que los hidrocarburos son lavados de manera periódica de los sedimentos, depositados en los materiales orgánicos del suelo y en los sedimentos de los arroyos aledaños. L. racemosa forma un sistema denso de raíces secundarias y terciarias que inducen la acumulación de petróleo. El microecosistema constituido por el RI y la RZ propician condiciones favorables para el establecimiento y colonización de microorganismos, que a su vez son los responsables de la mineralización de compuestos orgánicos como glucosa, polímeros como la celulosa, hidrocarburos alcanos e hidrocarburos policíclicos bajo condiciones aeróbicas y anaeróbicas (Muratova et al., 2012; Maier \& Gentry, 2015). Bajo estas circunstancias ocurre el proceso de atenuación de hidrocarburos a través de la rizodegradación, que según Björklof, Salminen, Sainio y Jorgensen (2008) es un proceso anaeróbico y aeróbico realizado por organismos en el humedal en el trópico, y es una tecnología reconocida por varios autores para remover entre 38.9, 61.6 y $71 \%$ de HTP en 12, 24 y 36 meses (RiveraCruz et al., 2016).

Densidades poblacionales y aislados de rizobacterias: Según Walker, Bais, Grotewold y Vivanco (2003) la colonización microbiana en el suelo es mayor en sitios donde ocurre la liberación y acumulación de exudados radicales. Estas moléculas aportan nutrimentos disponibles para la microbiota, en consecuencia estimulan el incremento de la densidad poblacional de bacterias y hongos por la existencia de fuentes nutritivas. Las bacterias diazotroficas fijadoras de $\mathrm{N}$ de vida libre, las BSP, Azotobacter y Azospirillum aprovechan los distintos exudados radicales (azúcares, polisacáridos, aminoácidos, péptidos y proteínas) que actúan como mensajeros para la interacción raíz-microbio en la epidermis de la raíz (Walker et al., 2003). En este contexto, en el espacio rizosférico del manglar pueden establecerse 
(Berg \& Smalla 2009; Drogue, Doré, Borland, Wisniewski-Dyé, \& Prigent-Combaret, 2012) aquellos grupos microbianos benéficos para los servicios ambientales.

El efecto del RI según Neumann y Römheld (2012) es la acumulación de compuestos de bajo peso molecular disponibles para las bacterias diazotróficas de vida libre que colonizan la rizodermis. Otras fuentes energéticas asociadas con los exudados incluyen el ácido poligalacturínico, ácidos di y tricarboxílicos tales como malato, citrato, oxalato y compuestos fenólicos. Se identificó que bajo condiciones de anegamiento en el manglar la colonización de BFN de vida libre, BSP y Azotobacter fue en el RI de la planta de mangle blanco, en la RZ la mayor colonización fue del grupo Azospirillum. De acuerdo con Klughest y Haaker (1984) y Deubel y Merbach (2005), el oxígeno es un requerimiento indispensable para las actividades nitrogenasa y fosfatasa durante la fijación de $\mathrm{N}$ de vida libre, al igual que para la solubilización bacteriana del fosfato. Según Marschner (2012) el suministro de oxígeno a las rizobacterias adheridas a la rizodermis ocurre a través de la difusión interna desde las hojas a las raíces del aerénquima, la planta lo bombea a la epidermis de la raíz y suelo mediante un sifón que cruza la pared de la célula vegetal (Gobat, Aragno, \& Matthey, 2004). Otra forma de sobrevivencia de las rizobacterias cuando se produce hipoxia y anoxia en el suelo es mediante el uso otros aceptores de electrones terminales para la respiración (Greenway, Armstrong, \& Colemer, 2006).

Nuestros resultados evidencian que en la planta de mangle blanco la bacteria Azospirillum forma mayor densidad en la RZ que en el RI. Resultados similares fueron reportados en la RZ de los pastos Cynodon plechtostachyus, Echinochloa polystachya y en Paspalum virgatum cultivados en suelos con 25000 a 65589 $\mathrm{mg} \mathrm{kg}^{-1}$ de HTP intemperizado (Rivera-Cruz, 2011). Otra investigación encontró también que en la RZ del pasto Leersia hexandra, contaminado con 6000 a $180000 \mathrm{mg} \mathrm{kg}^{-1}$ de HTP, las poblaciones alcanzaron de 3 a $24 \times 10^{2}$ UFC gramo de suelo (Arias-Trinidad et al., 2017). La importancia del grupo de bacterias Azospirillum (Bottomley \& Myrold, 2015) es porque provee entre 5 a $30 \%$ del total de $\mathrm{N}$ acumulado por la planta. La mayor proporción de Azospirillum en RZ se explica porque interactúan tanto con la raíz y suelo, por su alta movilidad a través de flagelos en medios líquidos y bajo severas limitaciones de oxígeno. Algunas cepas utilizan como electrones al $\mathrm{NO}_{3}, \mathrm{NO}_{2}$ o $\mathrm{N}_{2} \mathrm{O}$, además son autotróficos de hidrógeno facultativos (Holt, Krieg, Sneath, Sraley, \& Williams, 1994). Por otro lado, la RZ contiene raíces dispersas que interactúan con el suelo, sitios con baja presión de oxígeno en el manglar que proveen un hábitat favorable para las bacterias diazotróficas aeróbicas y microerofílicos (Zuberer, 1990).

Flores-Meireles, Winans y Holguin (2007) identificaron que la RZ de la planta de mangle Avicennia germinans es un micro ambiente favorable y selectivo para el establecimiento de bacterias diazotróficas, esto fue encontrado también por Zuberert y Silver (1978) quienes contaron de $2.9 \times 10^{3}$ a $5.9 \times 10^{3} \mathrm{UFC} / \mathrm{g}$ de bacterias heterótrofas fijadoras de $\mathrm{N}$ asociadas con sedimentos de Avicennia. Franco et al. (2012) reportaron la estructura y diversidad de grupos de bacterias de vida libre, Azospirillum spp y Azotobacter spp en sedimentos de manglar; por otro lado, Rodríguez-Rodríguez et al. (2016) contaron poblaciones de $520 \times 10^{2}$ UFC fijadoras de $\mathrm{N}$ de vida libre en $\mathrm{RZ}$ del pasto L. hexandra en pantano con $7572 \mathrm{mg} \mathrm{kg}^{-1}$ de HTP, respecto a suelo sin contaminación (180x10² UFC).

La colonización de las BSP fue mayor en el RI y en la RZ en suelos con altos contenidos de carbono orgánico y con limitada disponibilidad de oxígeno por el anegamiento del suelo orgánico. Estudios bajo condiciones similares ya han sido realizados (Deubel \& Merbach, 2005), los resultados también especifican que las BSP, en ambientes con baja disponibilidad de oxígeno, incorporan altas cantidades de $\mathrm{P}$ en forma de polifosfatos. Estos autores también afirman que las BSP se establecen en sustratos con abundancia de compuestos fosfatados de bajo peso molecular derivados de los exudados radicales y bacterianos. El efecto positivo del petróleo en la población de BSP fue reportado por Rodríguez-Rodríguez et al. (2016), encontraron $700 \times 10^{3}$ UFC en la RZ del pasto 
tropical L. hexandra en suelo con $5574 \mathrm{mg}$ $\mathrm{kg}^{-1}$ de HTP, respecto a la densidad poblacional $150 \times 10^{3}$ UFC en suelo no contaminado. Otro efecto reportado es el efecto rizosfera del orden de 10 veces respecto al SNR. El efecto RZ ha sido reportado por Radwan, AI-Awadhi, Sorkhoh y EI-Nemr (1998) en el sistema radical de Vicia faba y también Lupinus albus en suelo con 1,5 y $10 \%$ de petróleo.

La bioestimulación inducida por el petróleo en las rizobacterias de la planta de $L$. racemosa también fue encontrada en estudios reportados por Amadi, Abbey y Nma (1996) de acuerdo con Abbasian, Lockington, Megharaj y Naidu (2016), Kirk, Klironomos, Lee y Trevors (2005) y Gaskin y Bentham (2010) mencionan que la biomasa microbiana incrementa en suelos con hidrocarburos del petróleo; ellos atribuyen esta positiva correlación de microbios degradadores de hidrocarburos con la distribución del petróleo en el ambiente. Además, tanto las rizobacterias como la raíz de L. racemosa, expuestas a petróleo intemperizado, exudan enzimas extracelulares esenciales para la degradación inicial de sustratos mezclados con alto peso molecular (Badalucco \& Kuikman, 2001), como es el caso de hidrocarburos del petróleo. Xiao-Dong. El-Alawi, Penrose, Glick y Greenberg (2004) identificaron que las rizobacterias mitigan el efecto tóxico de los contaminantes en la planta durante el cometabolismo exudando la enzima ácido 1-aminociclopropano-1-carboxílico. Las monooxigenasas y dioxigenasas también podrían estar involucradas (Pothuluri \& Cerniglia, 1994) mediante la hidrólisis del aceite degradado en presencia de oxígeno. Esta investigación no demostró la presencia de enzimas, que debe ser realizado por futuros estudios, sin embargo, la presencia de rizobacterias asociadas con la RZ de L. racemosa puede atribuírsele a los exudados enzimáticos.

Las bacterias diazotróficas de vida libre pertenecientes a los grupos Azotobacter, Azospirillum y BSP, encontradas en el RI y en la RZ de $L$. racemosa, indican que en condiciones de contaminación con petróleo intemperizado y anegamiento, se establecen cerca de la raíz de mangle, probablemente por el aprovechamiento de los exudados radicales que contienen altos niveles de carbono y energía. Según
Weiss, Camack y Koropalov (1991) en suelo del bosque de manglares, con altos contenidos de materia orgánica, la enterasa hidroliza la materia orgánica y produce monómeros y oligómeros que aprovechan las células bacterianas que se oxidan por las deshidrogenasas, lo que proporciona la energía necesaria para su multiplicación (Meyer-Reil \& Koster, 2000; Fenchel, King, \& Blackburn, 2012). Las BFN de vida libre para establecerse requieren bajas concentraciones de $\mathrm{N}_{2}$ y condiciones macroerofilicas necesarias para la expresión y regulación estructural de la nitrogenasa (Glick, Patten, Holguin, \& Penrose, 1999). En cuanto a las BSP requieren carbonatos de fosfatos y ácidos glucónico (glucosa dehidrogenasa) (Nehl \& Knox, 2006). Estos grupos de bacterias han sido reportadas en manglares (Olguín, Hernández, \& Sánchez-Galvan, 2007; Flores-Mireles et al., 2007; Franco et al., 2012).

El aislamiento de Azotobacter, Azospirillum y de BSP extraídos de la RI, del RZ y del SNR de L. racemosa bajo condiciones de suelo contaminado con petróleo intemperizado, indica que estas bacterias diazotróficas quizá han desarrollado mecanismos de adaptación. Estudios anteriores (Leahy \& Colwell, 1990) reportan que es probable que estas modificaciones sean del tipo que induce y/o reduce las enzimas específicas, posee respuesta selectiva enriquecimiento de organismos capaces de transformar hidrocarburos de interés. Estos mecanismos permiten a las bacterias utilizar como fuente carbono y energía a los hidrocarburos, propiedad que ha sido reportada en un gran número de aislados colectados en diferentes ambientes (Leahy \& Colwell, 1990; Barrios-San Martin et al., 2012; Madigan et al., 2015).

Actividad microbiana: El RI es una zona de la planta que registra alta actividad microbiana por la presencia de exudados orgánicos e inorgánicos aprovechados por los microorganismos para su nutrición (Brady \& Weil, 2008). En nuestro estudio la actividad microbiana fue alta en el RI de la planta de mangle L. racemo$s a$ comparada con la actividad en el RZ y en el SNR, tanto en suelos con petróleo (1 797, 3 294, 5249 y $10389 \mathrm{mg} \mathrm{kg}^{-1}$ ) como en aquellos no contaminados. La respiración microbiana 
fue mayor en el RI (Fig. 4 y Fig. 5) de los cuatro suelos evaluados y también la respuesta fue similar en los cinco tiempos evaluados (días 7, 14, 21, 42 y 63). Asimismo, se identificaron dos fases marcadas en la cinética microbiana: la logarítmica y la de muerte. Esto es atribuible porque la microflora nativa después de siete días sintetiza los metabolitos esenciales y promueve el crecimiento microbiano exponencial, proceso que se aprecia por el incremento de la respiración microbiana (fase exponencial). De manera muy pronunciada continúa la fase de muerte a partir del día 21 en todos los suelos y tiempos evaluados, aquí es evidente la disminución de la liberación de $\mathrm{CO}_{2}$. Esta tendencia muestra (Madigan et al., 2015) que el final del proceso la célula muere, aunque pueden permanecer algunas células viables durante meses o año.

El efecto positivo del RI de L. racemosa en la respiración microbiana, en los cuatro suelos, con y sin contaminación petróleo, sugiere que está relacionado con su composición. Se encontró que el RI tiene mayor cantidad de raíces respecto a la $\mathrm{RZ}$, en donde se hospedan microorganismos diazotróficos de asociación libre y simbióticos (Marschner, 2012). Sin embargo, el incremento también puede estar relacionado con la tasa de respiración de tejidos inactivos de la raíz de $L$. racemosa cultivado bajo condiciones in vitro. Bajo estas condiciones en laboratorio la acumulación de exudados radicales puede estimular la formación de sustrato para la respiración microbiana, de modo que las condiciones nutritivas nuevamente son favorables para las siguientes generaciones microbianas. Al respecto Killham (1994) y Lynch, Marschner y Rengel (2012) indican que los microorganismos heterótrofos estimulan la fragmentación y mineralización de la materia orgánica, y los fragmentos y minerales son integrados a las partículas del suelo por microorganismos especializados.

El efecto positivo de la RI de L. racemosa en la respiración microbiana fue similar que los resultados de Rodríguez-Rodríguez et al. (2016). Estos autores reportaron incremento de la liberación de $\mathrm{CO}_{2}$ en el RI del pasto lambedor (Leersia hexandra) en humedales contaminados con $7552 \mathrm{mg} \mathrm{kg}^{-1}$ de petróleo intemperizado en comparación al suelo sin planta 63 días después de la incubación. Timmerman, Fuller y Burton (2003) y Jing, He y Yang (2008) argumentan que el RI favorece la actividad microbiana y el contenido de carbono del suelo. Ambos parámetros están relacionados con la oxidación de carbono por microorganismos en condiciones aerobias. Sin embargo, en nuestro estudio la presencia de los HTP inhibió la emisión de $\mathrm{CO}_{2}$ en RI, RZ y SNR de L. racemosa en comparación con el suelo sin hidrocarburos (Fig. 4 y Fig. 5). Los resultados de la incubación del día 21 muestran que el aumento de la cantidad de HTP en el RI inhibió la respiración en el S4 en relación con el suelo control (S1). La mayor disminución de $\mathrm{CO}_{2}$ ocurrió en el RI y en la RZ del S4, contaminado con $10389 \mathrm{mg}$ de HTP.

Rodríguez-Rodríguez et al. (2016) obtuvieron resultados similares el día 63 después de la incubación, encontraron que disminuyó 22.7 \% la emisión de $\mathrm{CO}_{2}$ en la RZ con petróleo intemperizado respecto al no contaminado. Siddiqui \& Adams (2002) obtuvieron resultados diferentes el día 20 después de la incubación, aumentó la emisión de $\mathrm{CO}_{2}$ derivado de suelo contaminado con diésel. Además, Riveroll-Larios, Escalante-Espinosa, FócilMonterrubio y Díaz-Ramírez (2015) reportaron aumento de emisión de $\mathrm{CO}_{2}$ en el suelo con aceite viejo en humedal.

El RI y la RZ de L. racemosa bioestimularon la respiración microbiana porque se liberó mayor cantidad de $\mathrm{CO}_{2}$ que en el SNR en suelo no contaminado y también en suelo contaminado (Fig. 5). La emisión de $\mathrm{CO}_{2}$ el día 21 de incubación fue 62.3 y $53.3 \mathrm{mg} \mathrm{CO}_{2} \mathrm{~g}_{\text {de }}$ suelo $^{-1}$ $\mathrm{d}^{-1}$ en RI y en RZ del suelo testigo, disminuyó a 58.9 y $51.76 \mathrm{mg} \mathrm{CO}_{2}$ g suelo $^{-1} \mathrm{~d}^{-1}$. La menor disminución en RI y en RZ puede atribuirse al sinergismo y la diversidad de la microflora que utilizan como fuente de carbono y energía a los hidrocarburos y exudados radicales (Atlas \& Bartha, 2002). La misma tendencia ocurrió en SNR pero con mayor disminución (18.3\%), esto se atribuye a la persistencia de los hidrocarburos recalcitrantes (compuestos cíclicos, aromáticos, asfáltenos, y resinas) derivados del petróleo intemperizado, que predominan en los suelos evaluados. La tasa de degradación 
de estos hidrocarburos es lenta porque se adsorben en la matriz del suelo (Maletic, Dalmacija, Roncevic, Agbaba, \& Ugarcina, 2011). Otro factor inhibidor para la vida de la microflora en el suelo es el potencial tóxico, mutagénico y carcinógeno de los hidrocarburos recalcintrantes que predominan en el petróleo intemperizado (policíclicos aromáticos, polares y asfaltenos). Estos hidrocarburos afectan la síntesis de proteína y limita el crecimiento microbiano (Pothuluri \& Cerniglia, 1994).

Declaración de ética: los autores declaran que todos están de acuerdo con esta publicación y que han hecho aportes que justifican su autoría; que no hay conflicto de interés de ningún tipo; y que han cumplido con todos los requisitos y procedimientos éticos y legales pertinentes. Todas las fuentes de financiamiento se detallan plena y claramente en la sección de agradecimientos. El respectivo documento legal firmado se encuentra en los archivos de la revista.

\section{AGRADECIMIENTOS}

El primer autor agradece al Consejo Nacional de Ciencia y Tecnología, de México, por la beca otorgada durante 2017 y 2018 como apoyo económico para la realización de sus estudios de Maestría en Ciencias. Al Colegio de Postgraduados en Ciencias Agrícolas por todo el apoyo económico para la adquisición de materiales necesarios durante la investigación en campo y en el micro-túnel.

\section{RESUMEN}

La evaluación del impacto del petróleo en la interacción suelo-raíz de la planta de mangle blanco, Laguncularia racemosa, es básica para identificar los cambios en la actividad microbiana y en el potencial biotecnológico para la remediación de Histosoles contaminados. El objetivo de la investigación fue evaluar la distribución espacial de los hidrocarburos totales del petróleo (HTP) en el suelo orgánico, la densidad poblacional de bacterias promotoras del crecimiento vegetal, así como la respiración microbiana en el rizoplano (RI) en la rizósfera (RZ) y en suelo no rizosférico (SNR) de L. racemosa. Una superficie de $8000 \mathrm{~m}^{2}$ de un Histosol afectado desde 1967 y 1968 se evaluó por derrame crónico de petróleo y lodos de perforación provenientes del pozo petrolero La Venta 248. Se seleccionaron 15 árboles de L. racemosa y se extrajeron muestras del
RI, RZ y SNR. Los HTP se extrajeron en equipo soxhlet con diclorometano durante ocho horas y se cuantificaron por gravimetría. La cantidad promedio extraída de HTP permitió la diferenciación de cuatro suelos (S) en el área evaluada, con valor promedio para el S1 de $1797 \mathrm{mg} \mathrm{kg}^{-1}$ (no contaminado para la normativa mexicana) y tres suelos contaminados: S2 con 3 294, S3: 5249 y S4: 10389 mg $\mathrm{kg}^{-1}$. Los resultados evidencian diferencias estadísticas (Duncan, $\mathrm{p} \leq 0.05$ ) entre medias de las variables evaluadas. La mayor acumulación de HTP fue $22962 \mathrm{mg} \mathrm{kg}^{-1}$, se extrajo del SNR en el S4. Las mayores densidades de bacterias fijadoras de N, solubilizadoras de P, Azospirillum y Azotobacter fueron bioestimuladas por la presencia de niveles altos de HTP en el suelo, sin embargo la respiración microbiana fue inhibida. Los resultados sugieren que $L$. racemosa es sostenible en suelos con petróleo intemperizado, y es un bioestimulador de la actividad microbiana para la atenuación natural.

Palabras clave: Azospirillum, Azotobacter, bacterias fijadoras $\mathrm{N}$, bacterias solubilizadoras de fosfatos, mangle blanco, respiración.

\section{REFERENCIAS}

Abbasian, F., Lockington, R., Megharaj, M., \& Naidu, R. (2016). The biodiversity changes in the microbial population of soils contaminated with crude oil. Current Microbiology, 72(6), 663-670.

Amadi, A., Abbey, S. D., \& Nma, A. (1996). Chronic effects of oil spill on soil properties and microflora of a rainforest ecosystem in Nigeria. Water, Air, and Soil Pollution, 86(1-4), 1-11

Arias-Trinidad, A., Rivera-Cruz, M. C., Roldán-Garrigós, A., Aceves-Navarro, L. A., Quintero-Lizaola, R. \& Hernández-Guzmán, J. (2017). Uso de Leersia hexandra (Poaceae) en la fitorremediación de suelos contaminados con petróleo fresco e intemperizado. Revista de Biología Tropical, 65(1), 21-30.

Atlas, M. R., \& Bartha, R. (2002). Ecología Microbiana y Microbiología Ambiental (4 ${ }^{\mathrm{a}}$ ed.). España: Pearson Educación.

Badalucco, L., \& Kuikman, J. P. (2001). Mineralization and Inmobilization in the Rhizosphere. In R. Pinto, Z. Veranimi, \& P. Nannipieri (Eds.), The Rhizosphere Biochemistry and Organic Substances at the SoilPlant Interface (pp. 159-196). New York: CRC Press.

Barrios-San Martín, Y., Acosta, S., Sánchez, A., Toledo, A., González, F., \& García, R. M. (2012). Study and isolation of aerobic hydrocarbon-degrading bacteria from Cuban shorelines. Biotecnología Aplicada, 29(2), 80-86.

Berg, G., \& Smalla, K. (2009). Plant species and soil type cooperatively shape the structure and function of microbial communities in the rhizosphere. FEMS Microbiology Ecology, 68(1), 1-13.

Björklöf, K., Salminen, J., Sainio, P., \& Jorgensen, K. (2008). Degradation rates of aged petroleum hydrocarbons are likely to be mass transfer dependent in 
the field. Environmental Geochemistry and Health, 30(2), 101-107.

Bottomley, J. P., \& Myrold, D. D. (2015). Biological N Inputs. In A. E. Paul (Ed.), Soil Microbiology Ecology and Biochemistry (pp. 447-470). San Diego, CA, U.S.A.: Academic Press Elsevier.

Brady, C. N., \& Weil, R. R. (2008). The Nature and Properties of Soil $\left(14^{\text {th }}\right.$ ed.). New Jersey: Pearson Prentice Hall.

Burns, K. A., \& Codi, S. (1998). Contrasting impacts of localized versus catastrophic oil spills in mangrove sediments. Mangrove and Salt Marshes, 2(2), 63-74.

Das, S., De, M., Ganguly, D., Maiti, T. K., Mukherjee, A., Jana, T. K., \& De, T. K. (2012). Depth integrated microbial community and physic-chemical properties in mangrove soil of Sundarban. Advances in Microbiology, 2(3), 234-240.

Demoling, F., Figueroa, D., \& Baath, E. (2007). Comparison of factors limiting bacterial growth in different soils. Soil Biology and Biochemistry, 39(10), 2485-2495.

Deubel, A., \& Merbach, W. (2005). Influence of microorganisms on phosphorus bioavailability in soils. In F. Buscot \& A. Varma (Eds.), Microorganisms in Soils: Roles in Genesis and Functions (pp. 177-191). Berlin: Springer-Verlag.

Díaz, P. G., Ruiz, C. J. A., Medina, G. G., Cano, G. M. A., \& Serrano, A. V. (2006). Estadisticas Climáticas Básicas del Estado de Tabasco (Periodo 1961-2003). México: INIFAP, CIRGOC, Campo Experimental Cotaxtla.

Döbereniner, J., Marriel, I. E, \& Nery, N. (1976). Ecological distribution of Spirillum lipoferum Beijerinck. Canadian Journal of Microbiology, 22(10), 164-1473.

Drogue, B., Doré, H., Borland, S., Wisniewski-Dyé, F., \& Prigent-Combaret, C. (2012). Which specificity in cooperation between phytostimulating rhizobacteria and plants. Research in Microbiology, 163(8), 500-510.

Dueñas, L. H., \& Nieto, R. C. (2010). Dendrología Tropical: Estudio y caracterización dendrológica de las principales especies forestales de la Amazonia Peruana. Peru: Universidad Nacional Amazónica de Madre de Dios.

Duke, N. C., \& Watkinson, A. J. (2002). Chlorophyll-deficient propagules of Avicennia marina and apparent longer term deterioration of mangrove fitness in oil polluted sediments. Marine Pollution Bulletin, 44(11), 1269-1276.

Fenchel, T., King, G. M., \& Blackburn, H. (2012). Bacterial Biochemistry: The Ecophysiology of Mineral Cycling. San Diego: Elsevier.

Flores-Mireles, A. L., Winans, S. C., \& Holguin, G. (2007). Molecular characterization of diazotrophic and denitrifying bacteria associated with mangrove roots. Applied and Environmental Microbiology, 73(22), 7308-7321.
Franco, D. A. C., Silva, P. M. C., Cotta, R. S., Dini-Andreote, F., Soares, L. F., Salles, F. J., ... Andreote, D. F. (2012). Abundance and Genetic Diversity of nifH Gene Sequences in Anthropogenically Affected Brazilian Mangrove Sediments. Applied Environmental Microbiology, 78(22), 7960-7967.

García, O. J. O. (2015). Bacterias reguladoras del crecimiento vegetal en Histosol contaminado con petróleo $y$ plantado con mangle (Tesis de Licenciatura). Universidad Popular de la Chontalpa. Cárdenas, Tabasco, México.

Gaskin, S., \& Bentham, R. (2010). Rhizoremediation of hydrocarbon-contaminated soil using Australian native grasses. Science of the Total Environment, 408(17), 3683-3688.

Glick, B. R., Patten, C. L., Holguin, G., \& Penrose, D. M. (1999). Biochemical and genetic mechanisms used by plant growth promoting bacteria. London: Imperial College Press.

Gobat, J. M., Aragno, M., \& Matthey, W. (2004). The Living Soil. Fundamentals of Soil Science and Soil Biology. New Hampshire: Science Publishers, Inc.

Greenway, H., Armstrong, W., \& Colemer, T. D. (2006). Condition leading to high $\mathrm{CO}_{2}(>5 \mathrm{kPa})$ in waterlogged-flooded soils and possible effects on root growth and metabolism. Annals of Botany, 98(1), 9-32.

Gundlach, R. E. (2018). Oil-related mangrove loss east of Bonny River, Nigeria. In C. Makowski \& C. Finkl (Eds.), Threats to Mangrove Forests Hazards, Vulnerability and Management (pp. 267-321). Boca Raton: Springer International.

Hinsinger, P., Gobran, G. R., Gregory, P. J., \& Wenzel, W. W. (2009). Rhizosphere: biophysics, biogeochemistry and ecological relevance. Plant and Soil, 32(1), 117-152.

Holt, J., Krieg, R. N., Sneath, A. H. P., Sraley, T. J., \& Williams, T. S. (1994). Bergey's Manual ${ }^{\circledR}$ of Determinative Bacteriology. Baltimore: Williams \& Wilkins.

Jenkinson, D. C. (1976). The effects of biocidal treatments on metabolism in soil-IV. The decomposition of fumigated organisms in soil. Soil Biology and Biochemistry, 8(3), 203-208.

Jing, Y., He, Z., \& Yang, X. (2008). Role of rhizobacteria in phytoremediation of heavy metal contaminated soils. Journal of Zhejiang University Science B, 8(3), 192-207.

Kathiresan, K. (2011). Eco-Biology of mangroves 1:50. In J. N. Metras (Ed.), Mangroves: Ecology, Biology and Taxonomy (pp. 1-50). New York: Nova Science Publishers, Inc.

Kathiresan, K., \& Qasim, S. Z. (2005). Biodiversity of mangrove ecosystems. New Delhi: Hindustan Publishing Corporation.

Ke, L., Yu, K. S. H., Wong, Y. S., \& Tam, N. F. Y. (2005). Spatial and vertical distribution of polycyclic aromatic 
hydrocarbons in mangrove sediments. Science of the Total Environment, 340(1-3), 177-187.

Killham, K. (1994). Soil Biology. New York: Cambridge University Press.

Kirk, L. J., Klironomos, N. J., Lee, H., \& Trevors, T. J. (2005). The effects of perennial ryegrass and alfalfa on microbial abundance and diversity in petroleum contaminated soil. Environmental Pollution, 133(3), 455-465.

Klughest, J., \& Haaker, H. (1984). Inhibition of nitrogenase activity by ammonium chloride in Azotobacter vinelandii. Journal of Bacteriology, 157(1), 148-151.

Leahy, G. J., \& Colwell, R. R. (1990). Microbial degradation of hydrocarbons in the environment. Microbiological Reviews, 54(3), 305-315.

Little, I. D., Holtzmann, K., Gundlach, R. E., \& Galperin, Y. (2018). Sediment Hydrocarbons in Former Mangrove Areas, Southern Ogoniland, Eastern Niger Delta, Nigeria. In C. Makowski \& C. Finkl (Eds.), Threats to Mangrove Forests Hazards, Vulnerability and Management (pp. 323-342). Boca Raton: Springer International.

Lynch, J., Marschner, P., \& Rengel, Z. (2012). Effect of Internal and External Factor on Root Growth and Development. In P. Marschner (Ed.), Marschner's Mineral Nutrition of Higher Plants ( $3^{\text {rd }}$ ed., pp. 331346). San Diego: Academic Press Elsiever.

Madigan, M. T., Martinko, J. M., Dunlap, P. V., \& Clark, D. P. (2015). Brock. Biología de los Microorganismos (12 ed.). España: Pearson Educación.

Maier, M. R., \& Gentry, J. J. (2015). Microorganisms and organic pollutants. In L. I. Pepper, P. C. Gerba, \& J. T. Gentry (Eds.), Environmental Microbiology (3 ${ }^{\text {rd }}$ ed., pp. 377-438). San Diego: Academic Press Elsevier.

Maletic, S. P., Dalmacija, B. D., Roncevic, S. D., Agbaba, J. R., \& Ugarcina, P. (2011). Impact of hydrocarbon type, concentration and weathering on its biodegadability in soil. Journal of Environmental Science and Health, Part A, 46(10), 1042-1049.

Marschner, P. (2012). Rhizosphere Biology. In P. Marschner (Ed.), Marschner's Mineral Nutrition of Higher Plants ( ${ }^{\text {rd }}$ ed., pp. 369-373). San Diego: Academic Press Elsevier.

Meyer-Reil, L. A., \& Koster, M. (2000). Eutrophication of marine waters: effects on benthic microbial communities. Marine Pollution Bulletin, 41(1-6), 225-263.

Morales-Guzmán, G., Ferrera-Cerrato, R., Rivera-Cruz, M. C., Torres-Bustillos, L. G., Arteaga-Garibay, R. I., Mendoza-López, M. R., ... Alarcón, A. (2017). Diesel degradation by emulsifying bacteria isolated from soils polluted with weathered petroleum hydrocarbons. Applied Soil Ecology, 121, 127-134.

Muratova, Y. A, Golubev, S. N., Dubrovskaya, E. V., Pozdnyakova, N. N., Panchenko, L. V., Pleshakova, E. V., ... Turkovskaya, O. V. (2012). Remediating abilities of different plant species grown in diesel-fuel-contaminated leached chernozem. Applied Soil Ecology, 56, 51-57.

Nehl, D. B., \& Knox, G. G. O. (2006). Significance of bacteria in the rhizosphere. In G. K. Mukerji, C. Manoharachary, \& J. Singh (Eds.), Microbial Activity in the Rhizosphere (pp. 89-119). Berlin: Springer.

Neumann, G., \& Römheld, V. (2012). Rhizosphere chemistry in relation to plant nutrition. In P. Marschner (Ed.), Mineral Nutrition of Higher Plants ( $3^{\text {rd }}$ ed., pp. 347368). San Diego: Academic Press Elsevier.

Olguín, E. J., Hernández, M. E., \& Sánchez-Galván, G. (2007). Contaminación de manglares por hidrocarburos y estrategias de biorremediación, fitorremediación y restauración. Revista Internacional de Contaminación Ambiental, 23(3), 139-154.

Orihuela, B. E., Tovilla, H. C., Franciscus, M. V. H., \& Álvarez, L. T. (2004). Flujo de materia en un manglar de la costa de Chiapas, México. Madera y Bosques, $10(2), 45-61$.

Orocio, C. J. A. (2014). Evaluación de los hidrocarburos del petróleo intemperizado en Histosol de un manglar en La Venta, Tabasco (Tesis de Licenciatura). Universidad Popular de la Chontalpa. Cárdenas, Tabasco, México.

Pepper, L. I., \& Gerba, P. C. (2015). Cultural Methods. In L. I. Pepper, P. C. Gerba, \& J. T. Gentry (Eds.), Environmental Microbiology ( $3^{\text {rd }}$ ed., pp. 195-243). San Diego: Academic Press Elsevier.

Pikovskaya, R. I. (1948). Mobilization of phosphorus in soil in connection with their vital activities of some microbial species. Mikrobiologya, 17, 362-370.

Pothuluri, V. J., \& Cerniglia, E. C. (1994). Microbial metabolism of polycyclic aromatic hydrocarbons. In R. G. Chaudry (Ed.), Biological Degradation and Bioremediation of Toxic Chemicals (pp. 1-12). Portland: Dioscorides Press.

Proffitt, E. C., \& Devlin, D. J. (1998). Are there cumulative effects in red mangroves from oil spill during seedling and sapling stages? Ecological Applications, 8(1), 121-127.

Purnobasuky, H., \& Suzuki, M. (2005). Funcional anatomy of air conducting network on the pneumatophores of a mangroves plant, Avicennia marina (Forsk.) Vierh. Asian Journal of Plant Sciences, 4(4), 334-437.

Quirós-Rodríguez, J. A., Medrano-Mangones, W., \& Santafé-Patiño, G. G. (2017). Esponjas (Porifera: Demospongiae) de raíces sumergidas de Rhizophora mangle en la bahía de Cispatá, Córdoba, Caribe colombiano. Revista Mexicana de Biodiversidad, 88(1), 80-85.

Radwan, S. S., AI-Awadhi, H., Sorkhoh, N. A., \& EI-Nemr, I. M. (1998). Rhizospheric hydrocarbon-utilizing microorganisms as potential contributors to phytoremediation for the oily Kuwaiti desert. Microbiological Research, 153(3), 247-251.

Reinhold, B., Hurek, T., Fendrik, I., Pot, B., Gillis, M., Kersters, K., ... De, L. J. (1987). Azospirilum halopraeferans sp. Nov., a nitrogen-fixing organism 
associated with roots of kallar grass (Leptochloa fusca (L.) Kunth). International Journal of Systematic and Evolutionary Microbiology, 37, 43-46.

Rennie, R. J. (1981). A single medium for the isolation of acetylene reducing (dinitrogen-fixing) bacteria from soils. Canadian Journal of Microbiology, 27(1), 8-14.

Rivera-Cruz, M. C. (2011). Bacterias y hongos en suelos contaminados con petróleo crudo en Tabasco. In M A. Gamboa, \& R. H. Rojas (Eds.), Recursos Genéticos Microbianos en la Zona Golfo-Sureste de México (pp. 77-96). Estado de México, México: Subsistema Nacional de Recursos Genéticos Microbianos (SUBNARGEM) SAGARPA.

Rivera-Cruz, M. C., Ferrera-Cerrato, R., Volke, H. V., Rodríguez, V. R., \& Fernández, L. L. (2002). Adaptación y selección de microorganismos autóctonos en medios de cultivos enriquecidos con petróleo crudo. Terra Latinoamericana, 20(4), 423-434.

Rivera-Cruz, C. M., Trujillo-Narcía, A., Trujillo-Rivera, E. A., Arias-Trinidad, A., \& Mendoza-López, M. R. (2016). Natural attenuation of weathered oil using aquatic plants in a farm in southeast Mexico. International Journal of Phytoremediation, 18(9), 877-884.

Riveroll-Larios, J., Escalante-Espinosa, E., Fócil-Monterrubio, R. L., \& Díaz-Ramírez, I. J. (2015). Biological activity assessment in Mexican tropical soils with different hydrocarbon contamination histories. Water Air and Soil Pollution, 226, 353.

Rodríguez-Rodríguez, N., Rivera-Cruz, M. C., TrujilloNarcía, A., Almaraz-Suárez, J. J., \& Salgado-García, S. (2016). Spatial distribution of oil and biostimulation through the rhizosphere of Leersia hexandra in degraded soil. Water Air and Soil Pollution, 227, 319.

Rojas, A., Holguin, G., Glick, B. R., \& Bashan, Y. M. (2001). Synergism between Phyllobacterium sp. (N2-fixer) and Bacillus licheniformis (P-solubilizer), both from a semiarid mangrove rhizhosphere. FEMS Microbiology Ecology, 35(2), 181-187.

Saravanakumar, K., Anburaj, R., Gomathi, V., \& Kathiresan, K. (2016). Ecology of soil microbes in a tropical mangrove forest of south east coast of India. Biocatalysis and Agricultural Biotechnology, 8, 73-85.

SAS. (2005). Statistical Analysis System.User's Guide (Ver. 9.1.3). Cary: SAS Institute, Inc.

SEMARNAT. (2002). Norma Oficial Mexicana NOM021-RECNAT-2000. Que establece las especificaciones de fertilidad, salinidad y clasificación de suelos. Estudios, muestreo y análisis. México: Secretaria del Medio Ambiente de Recursos Naturales.

SEMARNAT. (2013). Norma Oficial Mexicana NOM138- SEMARNAT/SSA1-2012. Límites Máximos
Permisibles de Hidrocarburos en Suelos y Lineamientos para el Muestreo en la Caracterización y Especificaciones para la Remediación. México: Secretaria del Medio Ambiente de Recursos Naturales.

Siddiqui, S., \& Adams, W. A. (2002). The fate of diesel hydrocarbons in soils and their effect on the germination of perennial ryegrass. Environmental Toxicology, $17(1), 49-62$.

Tam, N. Y., Wong, W. Y. T., \& Wong, Y. S. (2005). A case study on fuel oil contamination in a mangrove swamp in Hong Kong. Marine Pollution Bulletin, 51(8-12), 1092-1100.

Timmerman, M. D., Fuller, L. G., \& Burton, D. L. (2003). The effects of a crude oil spill on microbiological indices of soil biological quality. Canadian Journal of Soil Science, 83(2), 173-181.

Trujillo-Narcía, A., Rivera-Cruz, M. C., Trujillo-Rivera, E. A., \& Roldán-Garrigos, A. (2018). Reintroducing plant coverage in a tropical wetland contaminated with oil and sulfate: rhizosphere effects on Desulfovibrio populations. Revista de Biología Tropical, 66(2), 908-917.

USEPA-3540C. (1996). Soxhlet extraction organics. SW-846 test methods for evaluating solid waste physical/chemical methods. Retrieved from http: // www. epa.gov/wastes/hazard/test methods/sw846/ pdfs/3540c.pdf

Walker, T. S., Bais, H. P., Grotewold, E., \& Vivanco, J. M. (2003). Root exudation and rhizosphere biology. Plant Physiology, 132(1), 44-51.

Weiss, R. F., Camack, E. C., \& Koropalov, V. M. (1991). Deep-water renewal and biological production in Lake Baikal. Nature, 349, 665-669.

Xiao-Dong, H., El-Alawi, Y., Penrose, M. D., Glick, R. B., \& Greenberg, M. B. (2004). Responses of three grass species to creosote during phytoremediation. Environmental Pollution, 130(3), 453-463.

Zhang, J., Cai, L., Yuan, D., \& Chen, M. (2004). Distribution and sources of polynuclear aromatic hydrocarbons in mangrove superficial sediments of Deep Bay, China. Marine Pollution Bulletin, 49(5-6), 479-486.

Zuberer, D., \& Silver, W. S. (1978). Biological dinitrogen fixation (acetylene reduction) associated with Florida mangroves. Applied Environmental Microbiology, 35(3), 567-575.

Zuberer, D. A. (1990). Soil and rhizosphere aspects of N2-fixing plant-microbe associations. In J. M. Lynch (Ed.), The Rhizosphere (pp. 317-353). New York: John Wiley and Sons. 